\title{
Effect of antioxidants and ACE inhibition on chemical modification of proteins and progression of nephropathy in the streptozotocin diabetic rat
}

\author{
N. L. Alderson ${ }^{1} \cdot$ M. E. Chachich ${ }^{1}$ N. Frizzell ${ }^{2}$ P. Canning ${ }^{2} \cdot$ T. O. Metz ${ }^{1} \cdot$ A. S. Januszewski ${ }^{1} \cdot$ N. N. Youssef ${ }^{1} \cdot$ \\ A. W. Stitt ${ }^{2}$ J. W. Baynes ${ }^{1,3} \cdot$ S. R. Thorpe ${ }^{1}$ \\ ${ }^{1}$ Department of Chemistry and Biochemistry, University of South Carolina, Columbia, South Carolina, USA \\ ${ }^{2}$ Department of Ophthalmology, Queens University, Belfast, Northern Ireland \\ ${ }^{3}$ School of Medicine, University of South Carolina, Columbia, South Carolina, USA
}

\section{Abstract}

Aims/hypothesis. This study was designed to determine whether inhibition of formation of AGE and advanced lipoxidation end-products (ALE) is a mechanism of action common to a diverse group of therapeutic agents that limit the progress of diabetic nephropathy. We compared the effects of the ACE inhibitor enalapril, the antioxidant vitamin $\mathrm{E}$, the thiol compound lipoic acid, and the AGE/ALE inhibitor pyridoxamine on the formation of AGE/ALE and protection against nephropathy in streptozotocin diabetic rats.

Methods. Renal function and AGE/ALE formation were evaluated in rats treated with the agents listed above. Plasma was monitored monthly for triglycerides, cholesterol, creatinine and TNF- $\alpha$, and 24-h urine samples were collected for measurement of albumin and total protein excretion. After 29 weeks, renal expression of mRNA for extracellular matrix proteins was measured, and AGE/ALE were quantified in skin and glomerular and tubular collagen.

Results. Diabetic animals were both hyperglycaemic and dyslipidaemic, and showed evidence of early nephropathy (albuminuria, creatinaemia). All interventions limited the progression of nephropathy, without affecting glycaemia. The order of efficacy was: pyridoxamine $\left(650 \mathrm{mg} \cdot \mathrm{kg}^{-1} \cdot \mathrm{day}^{-1}\right)>$ vitamin $\mathrm{E}$ $\left(200 \mathrm{mg} \cdot \mathrm{kg}^{-1} \cdot \mathrm{day}^{-1}\right)>$ lipoic acid $\left(93 \mathrm{mg} \cdot \mathrm{kg}^{-1} \cdot \mathrm{day}^{-1}\right)$ $\sim$ enalapril $\left(35 \mathrm{mg} \cdot \mathrm{kg}^{-1} \cdot \mathrm{day}^{-1}\right)$. Pyridoxamine also significantly inhibited AGE/ALE accumulation in tissues; effects of other agents were mixed, but the degree of renoprotection was consistent with their effects on AGE/ALE formation.

Conclusions/interpretation. All interventions inhibited the progression of nephropathy at the doses studied, but the maximal benefit was achieved with pyridoxamine, which also limited dyslipidaemia and AGE/ALE formation. These experiments indicate that the more effective the renoprotection, the greater the inhibition of AGE/ALE formation. For optimal protection of renal function, it would be beneficial to select drugs whose mechanism of action includes inhibition of AGE/ALE formation.

Keywords ACE inhibitor AGE/ALE . AGE/ALE-inhibitor · Antioxidants · Enalapril · Lipoic acid · Nephropathy $\cdot$ Pyridoxamine $\cdot$ Vitamin E
Received: 15 January 2004 / Accepted: 30 April 2004

Published online: 28 July 2004

(C) Springer-Verlag 2004

\section{S. R. Thorpe ( $)$}

Department of Chemistry and Biochemistry,

University of South Carolina, Columbia, South Carolina, USA

E-mail: thorpe@mail.chem.sc.edu

Tel.: +1-803-777-7399, Fax: +1-803-777-7272

Abbreviations: ALE, advanced lipoxidation end-products .

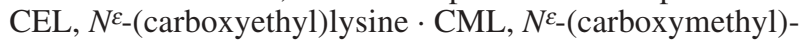
lysine $\cdot \mathrm{GlcHb}$, total glycated haemoglobin $\cdot$ MDA-lysine, malondialdehyde-lysine

\section{Introduction}

Accelerated chemical modification of proteins by glycation and glycoxidation reactions and accumulation of AGE in tissue proteins are implicated in the pathogenesis of diabetic nephropathy [1] and other complications [2]. The increase in AGE formation in diabetes is variously attributed to: (i) the increase in glycaemia alone [3]; (ii) an increase in oxidative stress, combined with the increase in glycaemia $[4,5]$; (iii) an increase in carbonyl stress, resulting from over- 
production of reactive dicarbonyl intermediates or defects in their detoxification pathways [6]; and (iv) an alternative hypothesis proposing that lipids are the primary source of chemical modification of proteins and that hyperglycaemia, with concurrent hyperlipidaemia, exacerbates formation of advanced lipoxidation end-products (ALE) in tissue proteins in diabetes [7]. The AGE hypothesis has been supported by studies demonstrating that treatment with AGE inhibitors, such as aminoguanidine [1, 8], OPB-9195 (2-isopropylidenehydrazono-4-oxo-thiazolidin-5-yl-acetanilide) [9] and pyridoxamine [10], has a profound inhibitory effect on the development of a range of complications, including nephropathy, in diabetic animals. However, despite the clear association between AGE and diabetic complications and the protective effects of AGE inhibitors, the results of other studies suggest that AGE are not directly involved in the pathogenesis of diabetic complications: thus aldose reductase inhibitors [11], ACE inhibitors and angiotensin receptor antagonists [12, 13, 14], protein kinase $\mathrm{C}$ inhibitors $[15,16]$, cerivastatin (a 3-hydroxy-3-methylglutaryl coenzyme A reductase inhibitor) [17] and benfotiamine (or thiamine) [18] have all been shown to have beneficial effects in animal models and/or clinical studies.

To explain these apparent contradictions, in this paper we propose and test the hypothesis that AGE/ALE inhibition may be a common mode of action for a variety of therapies that retard the development of diabetic nephropathy, but do not affect hyperglycaemia. In support of this hypothesis, aldose reductase inhibitors, which protect against the development of nephropathy in the diabetic rat, also inhibit AGE formation [11]. Similarly, ACE inhibitors and angiotensin receptor antagonists inhibit the formation of AGE in the kidney of diabetic rats $[12,13]$.

The current study, therefore, was designed to compare the effects of the AGE inhibitor pyridoxamine, the antioxidants vitamin $\mathrm{E}$ and $\alpha$-lipoic acid, and the ACE inhibitor enalapril on the formation of AGE and on the development of nephropathy in the streptozotocin-induced diabetic rat. Vitamin E [19, 20, 21], lipoic acid $[22,23,24,25,26]$ and ACE inhibitors [12, 13] have been shown to protect against diabetic complications in animal models, but their effects on AGE formation have not been evaluated by chemical methods. In the present work, experiments with vitamin $\mathrm{E}$ were designed primarily to address the role of lipid peroxidation in the formation of AGE/ALE, while recognising that it is also an inhibitor of protein kinase $\mathrm{C}$ [15]. Experiments with lipoic acid aimed to address the role of glutathione-dependent detoxification pathways in the inhibition of AGE/ALE formation. Enalapril was studied to investigate the role of hypertension. The evaluation of the effects of these agents on glycaemia, lipidaemia and AGE/ALE formation should also provide insight into the role of lipids and lipid peroxidation in the chemical modification of proteins and the development of nephropathy in diabetes.

To avoid confusion in the interpretation of experimental results, it should be noted that some com-

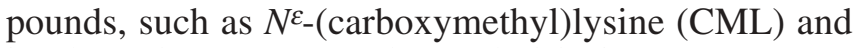
its homologue, $N^{\varepsilon}$-(carboxyethyl)lysine (CEL), are considered to be AGE/ALE [27]. These protein modifications may be formed from carbohydrates or lipids in vitro, making their origin on protein in vivo uncertain. In contrast, the protein cross-link, pentosidine, is considered to be an AGE because it originates exclusively from carbohydrates, while malondialdehyde-lysine (MDA-lysine) and 4-hydroxynonenal-lysine are formed on protein exclusively from products of lipid peroxidation and are considered to be ALE.

\section{Materials and methods}

Materials. Pyridoxamine-( $\mathrm{HCl})_{2}$, streptozotocin, enalapril maleate and clinical assay kits were obtained from Sigma-Aldrich, (St Louis, Mo., USA). $R$ - $\alpha$-lipoic acid was a generous gift from K. Kraemer (BASF, Ludwigshafen, Germany). Rodent (Diet W-8604) chow, with or without vitamin E ( $\alpha$-tocopherol, $1000 \mathrm{IU} / \mathrm{kg}$ ) or lipoic acid $(0.05 \%)$, was prepared by Teklad (Madison, Wis., USA). Unless otherwise indicated, other reagents were of the highest quality obtainable from SigmaAldrich.

Animal studies. All animal studies were carried out with the approval of the Institutional Animal Care and Use Committee of the University of South Carolina. Female Sprague-Dawley rats (weight $\sim 175 \mathrm{~g}$ ) were obtained from Harlan (Indianapolis, Ind., USA). Diabetes was induced by a single i.v. injection of streptozotocin $(45 \mathrm{mg} / \mathrm{kg}$ in $100 \mathrm{mmol} / \mathrm{l}$ sodium citrate buffer, $\mathrm{pH} 4.5)$. Non-diabetic animals $(n=12)$ were sham-injected with buffer only. Animals with plasma glucose levels higher than $16 \mathrm{mmol} / \mathrm{l}$ were included in the study. One week after induction of diabetes, rats were divided randomly (16 per group) into an untreated diabetic group and four treated diabetic groups, receiving either pyridoxamine_(1 g/l) or enalapril $(50 \mathrm{mg} / \mathrm{l})$ in the drinking water, or vitamin E or lipoic acid in the diet. All animals were housed individually, with a light/dark cycle of $12 \mathrm{~h}$ each and free access to food and water. In order to limit hyperglycaemia and ensure that animals maintained body weight, diabetic rats received 3 IU of ultralente insulin (Humulin U, Eli Lilly, Indianapolis, Ind., USA) three times per week; this was increased to 5 IU after Week 15 to adjust for the increase in body weight. The study was carried out over 29 weeks.

Plasma analyses for glycaemia and dyslipidaemia. Glycaemia was monitored monthly by measurement of plasma glucose and total glycated haemoglobin $(\mathrm{GlcHb})$. Blood was obtained from the tail vein using heparinised microhematocrit tubes, and the plasma was recovered by centrifugation at $4{ }^{\circ} \mathrm{C}$. Plasma glucose was measured using the Trinder assay kit: (SigmaAldrich kit number 315), and GlcHb was measured on whole blood by boronate affinity chromatography (Sigma-Aldrich kit number 442-B). Total plasma cholesterol and triglycerides were measured using Sigma-Aldrich kits for total cholesterol (number 352) and total triglycerides (GPO Trinder kit, number 37). 
Plasma and urinary cytokine assays. Plasma TNF- $\alpha$ was assayed using an ELISA kit from R\&D Systems (Minneapolis, Minn., USA). TGF- $\beta_{1}$ was measured in an aliquot of $24-h$ urine (see below). Urine was concentrated $(1 \mathrm{ml}$ in the nondiabetic group, $\sim 10 \mathrm{ml}$ all diabetic groups) to $\sim 0.1 \mathrm{ml}$ under vacuum using a Savant Speed-Vac (Savant Instruments, Farmingdale, N.Y., USA) and total TGF- $\beta_{1}$ was then measured by ELISA (Promega, Madison, Wis., USA) after activation with $\mathrm{HCl}$ according to the manufacturer's directions.

Nephropathy. Progression of nephropathy was assessed by monthly measurements of 24-h urinary albumin and total protein excretion and plasma creatinine concentrations. For urinary measurements, rats were housed in metabolic cages for $24 \mathrm{~h}$; several drops of toluene were added to the urine collection beaker to inhibit microbial growth. Urinary albumin was quantified by a competitive ELISA as described previously [10]. Total urinary protein was measured using the Sigma-Aldrich Microprotein-PR Kit; a correction $(<10 \%)$ was applied for the pyridoxamine content of the sample [10]. Plasma creatinine concentration was measured by the Jaffé picric acid procedure using Sigma-Aldrich kit number 555-A.

Necropsy and tissue sampling. Blood was drawn from anaesthetised (isofluorane) rats by heart puncture and transferred into heparinised vacutainer tubes on ice. Rats were killed by over-anaesthetisation, and kidneys were removed, decapsulated, rinsed in PBS and weighed. One whole kidney and onehalf of the second kidney were immediately frozen at $-70{ }^{\circ} \mathrm{C}$. A small portion of the second half of the remaining kidney was immediately placed in RNA-later (Ambion, Woodward, Tex., USA) for RNA extraction, and the remainder sliced into 2 $\mathrm{mm}$ slices and placed in $10 \%$ buffered formalin for immunohistochemical analyses. Abdominal skin $\left(\sim 2 \mathrm{~cm}^{2}\right)$ was also removed, rinsed in cold PBS and stored at $-70{ }^{\circ} \mathrm{C}$ until analysed. Blood was separated into plasma and red blood cells within $30 \mathrm{~min}$ by centrifugation at $4{ }^{\circ} \mathrm{C}$; aliquots of plasma were stored at $-70{ }^{\circ} \mathrm{C}$ until analysed.

Preparation and analyses of skin collagen. The insoluble fraction of skin collagen was prepared by scraping the skin to remove hair and adventitious tissue, followed by sequential extraction with $1 \mathrm{~mol} / \mathrm{l} \mathrm{NaCl}, 500 \mathrm{mmol} / \mathrm{l}$ acetic acid and chloroform/methanol $(2: 1 \mathrm{v} / \mathrm{v})$ as described previously [28]. The collagen was lyophilised and stored at $-70{ }^{\circ} \mathrm{C}$ until analysed. For analysis of AGE/ALE by mass spectrometry, collagen (2-3 mg) was reduced with a final concentration of $400 \mathrm{mmol} / 1 \mathrm{NaBH}_{4}$, hydrolysed in $6 \mathrm{~mol} / \mathrm{l} \mathrm{HCl}$ for $24 \mathrm{~h}$ at $110{ }^{\circ} \mathrm{C}$, then dried under vacuum. Fructose-lysine, a measure of glycation of collagen, was measured in unreduced samples. Fructose-lysine, CML, CEL and MDA-lysine were converted into their trifluoroacetyl-methyl ester derivatives and quantified by isotope dilution, selected ion monitoring gas chromatography-mass spectrometry as described previously [28, 29]. Pentosidine was measured in collagen samples reduced with $100 \mathrm{mmol} / 1 \mathrm{NaBH}_{4}$, hydrolysed in acid as above, and analysed by reversed-phase HPLC [30]. Measurements of each analyte in skin collagen or in renal tissue (see below) were carried out in a single batch to avoid inter-assay variation.

Isolation and analyses of glomeruli and tubules. Frozen kidneys were thawed and separated into glomeruli and tubules using a series of graded sieves [31, 32]. The final cell isolates were washed in PBS and stored at $-70{ }^{\circ} \mathrm{C}$ until processed for chemical analyses, at which time the pellets were thawed and suspended in 1-2 $\mathrm{ml}$ of deionised water. Protein concentration was estimated by the Lowry procedure [33], which was altered to pre-digest the cell samples at $37{ }^{\circ} \mathrm{C}$ for $15 \mathrm{~min}$ in $100 \mathrm{mmol} / \mathrm{l} \mathrm{NaOH}$ in order to obtain consistent results. An aliquot ( $\sim 5$ and $10 \mathrm{mg}$ protein for glomeruli and tubules respectively) was removed for pentosidine analysis, and a separate aliquot ( 3 and $5 \mathrm{mg}$ for glomeruli and tubules respectively) was taken for AGE/ALE analysis. Samples for pentosidine and for other AGE/ALE analyses were reduced with $100 \mathrm{mmol}$ and $400 \mathrm{mmol} / \mathrm{l} \mathrm{NaBH}_{4}$ respectively; after reduction, protein was precipitated at $4{ }^{\circ} \mathrm{C}$ using trichloroacetic acid. The pellet was re-dissolved in $500 \mathrm{mmol} / \mathrm{l} \mathrm{NaOH}$, and the protein precipitation repeated, after which the protein pellet was washed once with trichloroacetic acid. Cold deionised water $(500 \mu \mathrm{l})$ was added to the final protein precipitates, the mixture vortexed thoroughly and lipids extracted with $3 \mathrm{ml}$ of ice-cold methanol : ether $(3: 1 \mathrm{v} / \mathrm{v})$. The samples were placed on ice for $10 \mathrm{~min}$, centrifuged at $2500 \mathrm{rev} / \mathrm{min}$ for $10 \mathrm{~min}(1000 \mathrm{~g})$ at $4{ }^{\circ} \mathrm{C}$ and the supernatant discarded. The delipidation procedure was repeated twice.

Delipidated glomerular and tubular protein used for pentosidine analyses were dried under a stream of nitrogen, hydrolysed in $6 \mathrm{~mol} / \mathrm{l} \mathrm{HCl}$ for $18 \mathrm{~h}$ at $110{ }^{\circ} \mathrm{C}$ then dried under vacuum. Pentosidine was recovered from acid hydrolysates of glomerular and tubular protein by chromatography on SPSephadex, then quantified by reversed-phase HPLC as described [34], except for modification of the chromatographic procedure. Separation of pentosidine in renal protein was carried out on a Vydac 219TP54 (5- $\mathrm{mm}$ particle size, $4.6 \times 250 \mathrm{~mm}$ ) reversed-phase column (Grace Vydac, Hesperia, Calif., USA) at a flow rate of $1 \mathrm{ml} / \mathrm{min}$ on a Waters HPLC system (Milford, Mass., USA). Gradient elution was conducted with solvent A (10 mmol/l heptafluorobutyric acid in water) and solvent $\mathrm{B}\left(60 \% \mathrm{CH}_{3} \mathrm{CN}\right.$ in $10 \mathrm{mmol} / \mathrm{l}$ heptafluorobutyric acid) using the following gradient: Time 0 min $15 \% \mathrm{~B} ; 20 \mathrm{~min}$ $15 \% \mathrm{~B} ; 25 \min 23 \% \mathrm{~B} ; 40 \min 23 \% \mathrm{~B} ; 60 \mathrm{~min} 70 \% \mathrm{~B} ; 65 \mathrm{~min}$ $70 \% \mathrm{~B} ; 75 \min 100 \% \mathrm{~B} ; 80 \min 100 \% \mathrm{~B}$.

For AGE/ALE analyses by selected ion monitoring gas chromatography-mass spectrometry, delipidated glomerular and tubular protein were dialysed against deionised water containing $1 \mathrm{mmol} / \mathrm{l}$ diethylenetriaminepentaacetic acid and then dried under vacuum. Heavy-labelled internal standards were added and the samples then hydrolysed in acid as above. The dried hydrolysates were redissolved in $1 \mathrm{ml}$ of $1 \%$ trifluoroacetic acid, and brown materials were removed using a 1-mg Sep-Pak (Waters, Milford, Mass., USA) equilibrated in 1\% trifluoroacetic acid. The sample flow-through and an additional $2 \mathrm{ml}$ of $1 \%$ trifluoroacetic acid containing $20 \%$ methanol were collected and dried under vacuum. Analytes were quantified by selected ion monitoring gas chromatography-mass spectrometry as described for skin collagen above.

Expression of basement membrane component mRNA. Measurements of renal mRNA expression were carried out in Belfast (Northern Ireland) on coded samples and the results were later unmasked in Columbia (S.C., USA). Renal RNA was extracted using the RNeasy Mini Kit (Qiagen, Crawley, UK), and the quantity of RNA in each sample was determined spectrophotometrically. The purity and quality of each RNA sample was estimated by visualisation of clear $18 \mathrm{~S}$ and $28 \mathrm{~S}$ ribosomal RNA bands after electrophoresing $1 \mu \mathrm{g}$ of each sample on a $1 \%$ agarose gel.

RNA samples were reverse transcribed into cDNA using the 1st Strand cDNA Synthesis Kit (Invitrogen, Carlsbad, Calif., USA) and the resulting single-stranded cDNA was amplified using real-time PCR with sequence-specific primers for rat fibronectin (forward primer: 5'-CGA AAC CAT GAA CTT TCT GC ACT GAC GAA GAG CCC TTA C-3'; reverse primer: 5'-CCT CAG TGG GCA CAC ACT CCAGA TAA CCG 
CTC CCA TTC C-3'), laminin ( $\beta$ chain) (forward primer: 5'ACA GAA GTC GAA GTG GTGAAA CCC TGA CCA ATG CCT CC-3'; reverse primer: 5'-GGC TAA TAA ATA GAG GGT AGGTTG TAG CAG CTG CTC AGC TTT CC-3') or collagen IV (forward primer: 5'-CGA AAC CAT GAA CTT TCT GCAGT TAC GCA AAT CCC TGT AAG-3'; reverse primer: 5'-CCT CAG TGG GCA CAC ACT CCGAG AAG AAC ATA GTG ATG CCC-3') to amplify 302,200, 888,253 and $503,176 \mathrm{bp}$ fragments respectively. The housekeeping gene, acidic ribosomal phosphoprotein [35] (forward primer: 5'-CGA CCT GGA AGT CCA ACT AC-3'; reverse primer 5'ATC TGC TGC ATC TGC TTG-3'), was also examined using the same cDNAs. Real-time RT-PCR was performed using a LightCycler rapid thermal cycler system (Roche, Hertfordshire, UK) according to protocols outlined previously [36, 37]. The specificity of the amplification reactions was confirmed by melting curve analysis and subsequently by agarose gel electrophoresis, and the data were analysed with the LightCycler analysis software and adjusted for housekeeping gene expression. To enable direct comparison between separate experiments $(n=3)$, the level of expression at each time point was expressed as a fraction of the total expression of each specific gene over all of the time periods studied.

Immunohistochemical studies. Fixed kidneys were embedded in paraffin wax and 5- $\mu \mathrm{m}$ sections were cut and mounted on silane-coated slides. After de-waxing and rehydration in PBS, the sections were treated with peroxidase block for $10 \mathrm{~min}$ (EnVision system Peroxidase DAB kit, Dako, Glostrup, Denmark) to quench endogenous peroxidase. After washing in PBS, the sections were blocked with $5 \%$ normal goat serum, $1 \%$ BSA, $0.01 \%$ Triton-X100 and then incubated in primary anti-CML antibody [37] at a 1:50 dilution for $1 \mathrm{~h}$ at room temperature. Controls were performed using primary antibody exclusion and rabbit non-immune serum. The sections were then washed gently in PBS prior to the addition of horseradish peroxidase-coupled polymer for $30 \mathrm{~min}$ (Dako). The slides were rinsed gently before application of the substrate chromogen for 10 min (Dako), after which the slides were immediately washed in PBS and then counter-stained in Meyer's Haematoxylin and mounted with Glycermount (Dako).

Statistical analysis. All samples were analysed in a blinded manner. Statistical analyses were performed using Instat (Graphpad software, San Diego, Calif., USA). Statistical significance was assessed by ANOVA with either Bonferroni or Tukey-Kraemer post-hoc tests. A $p$ value of less than or equal to 0.05 was considered to be statistically significant.

\section{Results}

Weight gain and mortality. At entry, the animals weighed between $188 \mathrm{~g}$ and $208 \mathrm{~g}$. All diabetic groups gained weight during the first 2 to 3 months of the study and maintained a mean body weight of $\sim 230 \mathrm{~g}$ thereafter. There were no significant differences in mean weights between any of the diabetic groups during the study. Non-diabetic animals gained weight throughout the 29 weeks, reaching a final value of $\sim 275$ g. All diabetic groups initially comprised 16 animals. At the end of the experiment, the numbers were reduced in the diabetic control $(n=12)$, enalapril $(n=15)$, pyridoxamine $(n=12)$, lipoic acid $(n=12)$ and vitamin $\mathrm{E}(n=13)$ groups. Eight of the diabetic rats were removed from the experiment because their blood glucose levels fell below $15 \mathrm{mmol} / \mathrm{l}$. Based on the average daily water consumption $(\sim 150 \mathrm{ml})$ of the pyridoxamine group, pyridoxamine intake was approximately $650 \mathrm{mg} \cdot \mathrm{kg}^{-1} \cdot \mathrm{day}^{-1}$. The average intake of enalapril was around $35 \mathrm{mg} \cdot \mathrm{kg}^{-1} \cdot \mathrm{day}^{-1}$ and, as reported elsewhere, blood pressure was essentially normalised in enalapril-treated rats compared with diabetic controls, whereas none of the other agents had any effect on hypertension [38]. During the final 2 months of the study, the mean daily food consumption of the lipoic acid and vitamin E groups approximated $43 \mathrm{~g}$ and $47 \mathrm{~g}$ per rat respectively, which translates into an estimated daily consumption of $\sim 93 \mathrm{mg} \cdot \mathrm{kg}^{-1}$ of lipoic acid and $\sim 200 \mathrm{mg} \cdot \mathrm{kg}^{-1}$ of vitamin E.

Glycaemic control. After the first month of the study, the mean plasma glucose for all diabetic groups was $25.0 \pm 1.0 \mathrm{mmol} / \mathrm{l}$, means $\pm \mathrm{SD}$ (with no statistical differences between any of the groups) compared with $5.3 \pm 0.2 \mathrm{mmol} / \mathrm{l}$, means $\pm \mathrm{SD}$, for non-diabetic rats. Non-diabetic animals had mean $\mathrm{GlcHb}$ values ranging from $6.6 \%$ to $7.0 \%$ throughout the study. For all diabetic groups, GlcHb rose steadily during the first 4 months, and stabilised at $12.1 \%$ to $12.7 \%$ thereafter, again with no statistical differences between any of the groups. As an additional assessment of glycaemic control, we measured the glycation product, fructose-lysine, in long-lived (insoluble) skin collagen. In the non-diabetic group, fructose-lysine levels were $4.4 \pm 0.5 \mathrm{mmol} / \mathrm{mol}$ lysine, means $\pm \mathrm{SD}$, and group means ranged from 22.6 to $23.9 \mathrm{mmol} / \mathrm{mol}$ lysine among all diabetic groups, with no statistically significant differences between the groups. Thus, the approximate five-fold increase in skin collagen fructoselysine levels observed for all diabetic groups compared with the non-diabetic animals was comparable to the increase in blood glucose. Therefore, outcome differences are not the result of an improvement in overall glycaemia by any intervention.

Dyslipidaemia. The increases in plasma triglycerides and cholesterol shown in Figure 1a and b indicate significant dyslipidaemia in untreated, diabetic control rats. By Week 29, there was approximately a fourfold increase in triglyceride levels $(4.6 \pm 0.15$ vs $0.95 \pm 0.1 \mathrm{mmol} / \mathrm{l}$, means $\pm \mathrm{SEM})$ and a $50 \%$ increase in cholesterol $(6.5 \pm 0.23$ vs $4.1 \pm 0.17 \mathrm{mmol} / \mathrm{l}$, means \pm SEM) in diabetic control rats compared with non-diabetic rats. Pyridoxamine suppressed the increase in plasma lipids throughout the study and, by Week 29, animals treated with this agent had plasma triglyceride and cholesterol concentrations of $2.25 \pm 0.57 \mathrm{mmol} / \mathrm{l}$ and $4.8 \pm 0.72 \mathrm{mmol} / \mathrm{l}$ (means $\pm \mathrm{SEM}$ ) respectively, $50 \%$ and $70 \%$ lower than those of diabetic control animals. Treatment with enalapril, lipoic acid or vitamin E did not significantly affect the rise in triglycerides, 

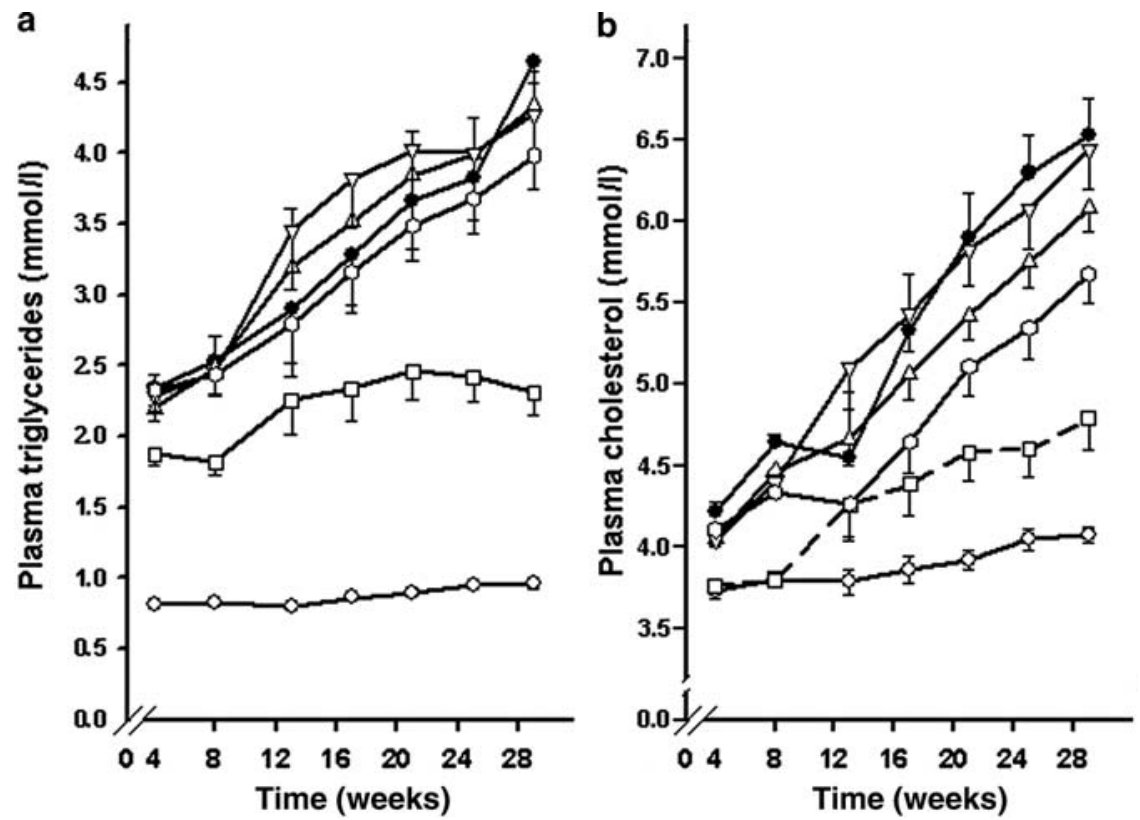

Fig. 1. Effect of treatment with pyridoxamine (squares), lipoic acid (inverted triangle), vitamin E (hexagon) or enalapril (triangle) on dyslipidaemia in diabetic rats. Non-fasting blood was sampled at the times indicated in treated rats and diabetic (filled circle) and non-diabetic (open circles) controls, and plasma levels of triglycerides (a) and cholesterol (b) were measured using commercial kits. Of all treatments, pyridoxamine was the most effective at limiting dyslipidaemia for both triglycerides and cholesterol in diabetic rats $(p<0.05-0.01)$ at all time points. Cholesterol levels in the vitamin $\mathrm{E}$ group were significantly different $(p<0.05)$ to those in the diabetic control group after Week 17. Data are shown as means \pm SEM

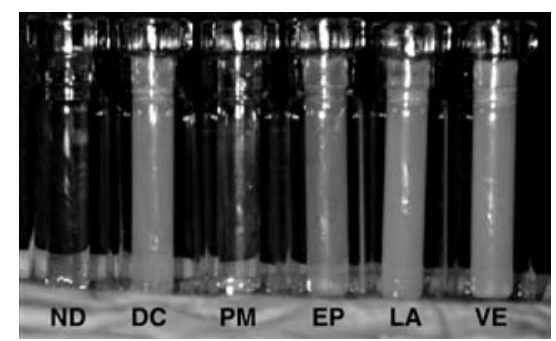

Fig. 2. Photograph of pooled plasma taken from each study group at necropsy. The milky appearance of the plasma in the diabetic control (DC) group emphasises the profound dyslipidaemia in this animal model. The plasma from the pyridoxamine (PM)-treated animals was appreciably clearer than that of all other groups, but still somewhat opalescent compared with non-diabetic (ND) animals. EP, enalapril; LA, lipoic acid; VE, vitamin $\mathrm{E}$

although vitamin $\mathrm{E}$ had an intermediate benefit in limiting the increase in plasma cholesterol. As shown in Figure 2, the plasma from all diabetic groups was turbid due to the high concentration of lipids, except for plasma from the pyridoxamine group, which was only slightly opalescent. NEFA were two to three times higher in diabetic rats compared with non-diabetic animals, but there were no differences between the various treatment groups (data not shown).

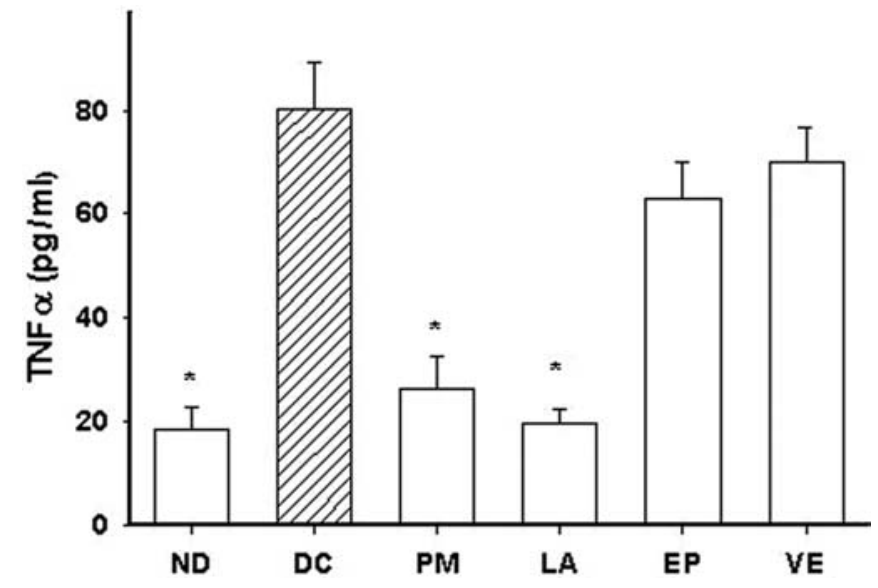

Fig. 3. Effect of treatment with pyridoxamine (PM), lipoic acid (LA), enalapril (EP) or vitamin E (VE) on plasma levels of TNF- $\alpha$ in diabetic rats. Both PM and LA normalised plasma levels of TNF- $\alpha$. Untreated diabetic animals (DC, hatched bar) showed a marked increase in plasma TNF- $\alpha$ concentrations compared with non-diabetic (ND) animals. TNF- $\alpha$ concentrations in the plasma of PM- and LA-treated animals were not statistically different to those in ND animals, while those in plasma of EP- and VE-treated animals were not statistically different than those in DC rats. Data are shown as means \pm SEM. * $p<0.001$ vs DC group

Plasma TNF- $\alpha$. The cytokine, TNF- $\alpha$, is known to be an important factor in the pathogenesis of diabetic nephropathy. Plasma TNF- $\alpha$ levels were nearly four times higher in diabetic control rats than in non-diabetic rats $(80.3 \pm 8.9$ vs $18.3 \pm 4.4 \mathrm{pmol} / \mathrm{ml}$, means \pm SEM, $p<0.001$; Fig. 3). Both pyridoxamine and lipoic acid treatments maintained plasma TNF- $\alpha$ concentrations at levels that were not statistically different from those in the non-diabetic group, whereas enalapril and vitamin $\mathrm{E}$ did not have any effect on the increase in this cytokine, despite demonstrating positive effects on renal function, as noted below. 

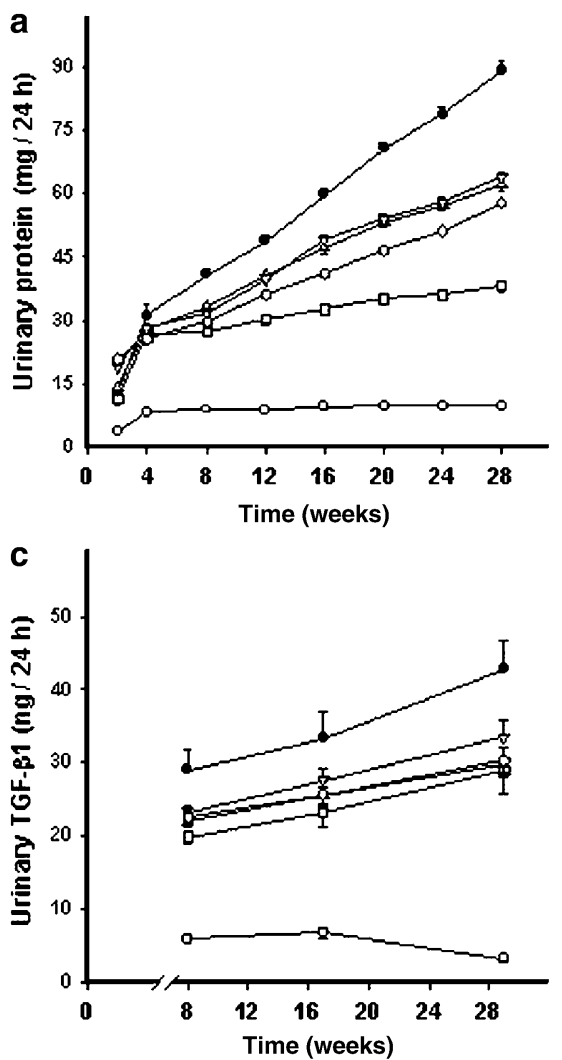

Fig. 4. Effect of interventions on renal function in diabetic rats. Urine (24-h samples) was collected at monthly intervals for measurement of total protein (a), albumin (b) and TGF- $\beta_{1}$ (c); monthly measurements of plasma creatinine (d) were also made. All interventions limited deterioration in renal function The order of efficacy in limiting renal damage was consistently pyridoxamine $>$ vitamin $E>$ enalapril $\approx$ lipoic acid. Data are shown as means \pm SEM. See text for statistical analyses. Results are shown as: non-diabetic (open circle), diabetic control (filled circle); pyridoxamine (square); enalapril (triangle); lipoic acid (inverted triangle); vitamin E (hexagon)

Renal function and transforming growth factor- $\beta 1$. The results of the biochemical measurements used to evaluate renal function are shown in Figure 4. By the end of the study, total 24-h urinary protein, albumin and TGF- $\beta_{1}$ were approximately 20,10 and 15 times higher respectively in diabetic control animals compared with non-diabetic rats, and plasma creatinine levels were approximately twice those in untreated, diabetic control rats. All interventions afforded statistically significant protection $(p<0.01$ compared with the diabetic control group) of renal function, based on inhibition of the increase in urinary protein and albumin excretion and plasma creatinine, thus confirming the renoprotective effects of these drugs at the doses used. Pyridoxamine treatment showed the greatest benefit, followed by vitamin $\mathrm{E}$, then enalapril and lipoic acid, with the latter two agents demonstrating approximately equal effects. We also measured the urinary excretion of total TGF- $\beta_{1}$, based on studies showing the utility of this measurement as an indicator of renal function $[39,40]$. While both pyridoxam-
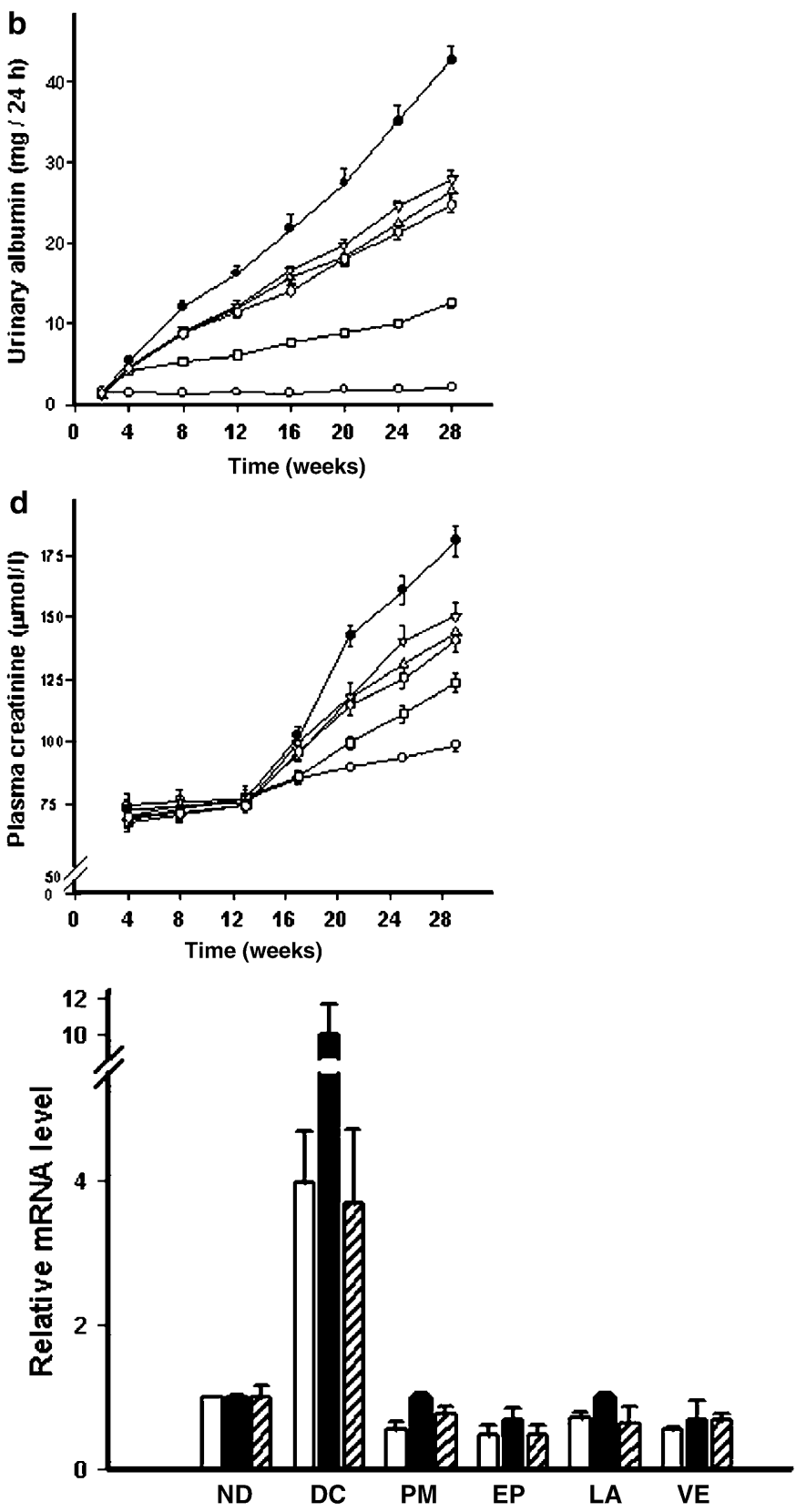

Fig. 5. Effect of interventions on renal matrix protein and TGF- $\beta_{1}$ mRNA expression. RT-PCR was used to measure mRNA levels for fibronectin (open bars), laminin (filled bars) and $T G F-\beta_{1}$ (hatched bars). Values for mRNA levels were averaged $(n=3)$ and then normalised to the value for non-diabetic (ND) group set as 1 for each mRNA. Data are shown as means \pm SD. DC, diabetic control; EP, enalapril; LA, lipoic acid; PM, pyridoxamine, VE, vitamin E

ine and vitamin $E$ were effective in reducing TGF- $\beta_{1}$ excretion $(p<0.01)$, the reduction was about $30 \%$. Similar trends were observed for lipoic acid and enalapril, but these did not achieve statistical significance.

Renal extracellular matrix and TGF- $\beta 1$ mRNA expression. The over-expression of extracellular matrix protein mRNAs (including laminin and fibronectin $\mathrm{mR}$ NAs) and $T G F-\beta_{1}$ mRNA in kidney is a characteristic 

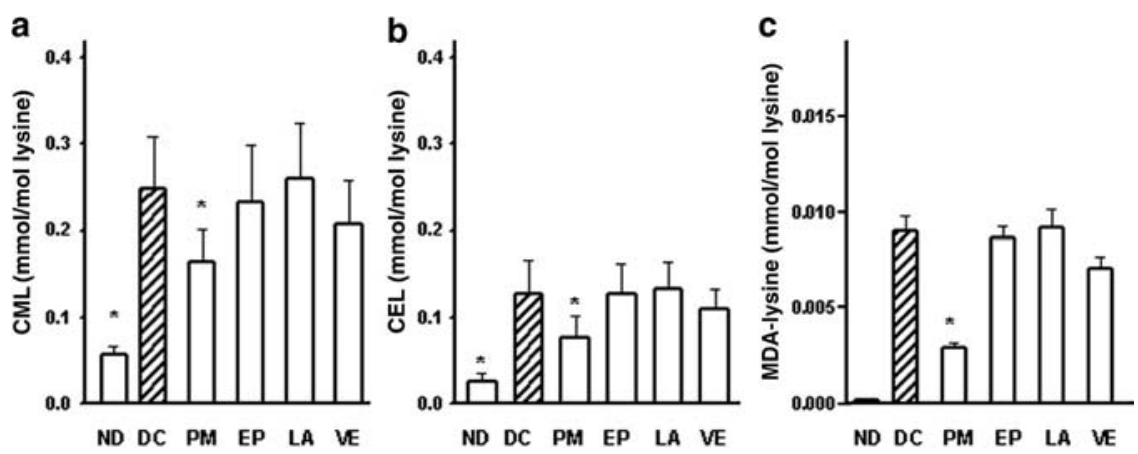

Fig. 6. Effect of interventions on the formation of AGE/ALE in skin collagen. At necropsy, skin was removed and collagen was extracted for measurement of CML (a), CEL (b) and MDA-lysine (c) by gas chromatography-mass spectrometry. Diabetic control animals (DC) showed a marked increase in all analytes compared with non-diabetic animals (ND). Only pyridoxamine (PM) limited the formation of AGE/ALE. Data are means \pm SD. $* p<0.01$ vs DC group. EP, enalapril; LA, lipoic acid; VE, vitamin E

feature of diabetic nephropathy. We quantified the corresponding mRNA levels for these cellular markers of renal disease to evaluate the effects of the various interventions. As shown in Figure 5, there was a large increase in mRNA encoding the various gene products in diabetic control rats, with the largest increase observed for laminin $(p<0.001$ for all mRNA species compared with non-diabetic rats). Despite the variable effects noted above on functional measures and TGF$\beta_{1}$ excretion, each intervention essentially normalised the renal expression of laminin, fibronectin and TGF$\beta_{1}$ mRNAs.

AGE/ALE in skin collagen. A major goal of the current research was to determine whether treatments that improved renal function would also affect the concentration of protein-bound AGE/ALE, either systemically or locally in tissues. Modification of insoluble skin collagen was used as a surrogate for systemic protein damage, since the collagen is relatively long-lived and is constantly exposed to plasma, where it would come in contact with products of autoxidation of carbohydrates and lipids. The graphs in Figure 6 show that concentrations of AGE/ALE, CML and CEL were approximately five times higher in diabetic control rats than in non-diabetic animals. Although pyridoxamine inhibited this rise by $\sim 40 \%$, none of the other treatments had an effect on the formation of CML or CEL in skin collagen. The ALE, MDA-lysine, was not detectable in the collagen of non-diabetic rats, but was measurable in all diabetic rats. Only pyridoxamine exhibited a treatment effect, limiting the amount of this adduct to $20 \%$ of that in all other diabetic groups; this is consistent with its unique ability to normalise plasma lipids. The 4-hydroxynonenal adduct to lysine [29] was not detectable in the collagen of any group. For all adducts, there was a trend for lower AGE/ALE in the vitamin E group, but the differences did not reach statistical significance. The collagen content of the AGE, pentosidine, was increased by approximately $60 \%$ in the skin of all diabetic rats, which is significantly less than the increase in other biomarkers, but it was not affected by any intervention (data not shown).

AGE/ALE in glomeruli and tubules. In previous experiments, AGE/ALE were measured in total renal collagen, but no statistically significant differences were observed between the non-diabetic and diabetic control groups [10]. It is possible that in the former studies the method used to isolate the collagen [28] resulted in the loss of more highly modified protein. In contrast, in the present study, in an effort to improve the sensitivity of the method for detection of potential differences in protein modification at sites of renal pathology, we separated renal tissue into glomeruli and tubules and then measured AGE/ALE in the total protein in each component (Figure 7). In glomeruli, both pentosidine and CML were increased by a factor of between two and three. Treatment with pyridoxamine substantially limited the increase, whereas none of the other treatments had a statistically significant effect. However, it should be noted that although the mean values for the vitamin $\mathrm{E}$ treatment group did not achieve statistical significance, they were comparable to those for the pyridoxamine group. For tubules, the changes were less pronounced. Although similar trends were seen in glomeruli and tubules, tubular concentrations of AGE/ALE were not significantly different between the non-diabetic and diabetic groups.

The photographs in Figure 8a and b show the immunohistochemical localisation of CML in glomeruli and tubules. In agreement with previous work [12], the overall intensity of CML staining in glomeruli is modest compared with that in tubules. In contrast to the immunohistochemistry, chemical measurement yielded similar levels of CML, CEL and pentosidine in glomerular and tubular collagen (Fig. 7). CML staining was only slightly increased in the glomeruli of diabetic animals, and none of the treatments significantly affected glomerular immunohistochemical staining or morphology (Fig. 8a). Pyridoxamine clearly protected against the increase in CML immunoreactivity in tubules (Fig. 8b), but this was not generally 

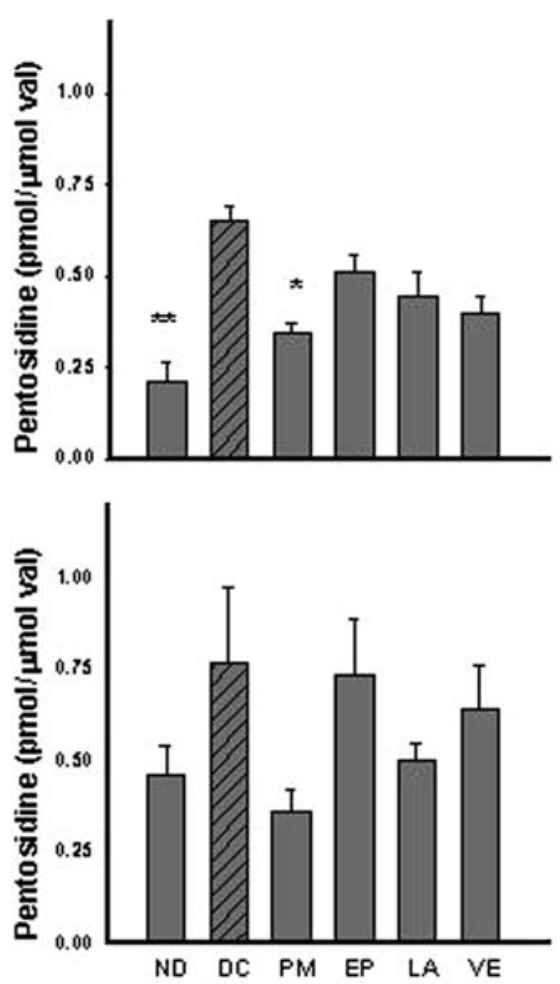

Fig. 7. AGE/ALE concentrations in renal tubules and glomeruli. Kidneys were separated by sieving into glomeruli (top panels) and tubules (bottom panels) and analysed for their content of pentosidine normalised to valine (val) (left panels) and CML normalised to lysine (right panels). CEL was also measured, but there were no significant differences between groups, except for non-diabetic (ND) compared with diabetic control animals $(p<0.05)$ in glomeruli. Neither MDA-lysine nor 4-hydroxynonenal-lysine were quantifiable in glomeruli or tubules. Data are shown as means \pm SEM.* $p<0.05$ vs DC; ** $p<0.01$ vs DC. EP, enalapril; LA, lipoic acid; PM, pyridoxamine; VE, vitamin $\mathrm{E}$

consistent with chemical measurements of AGE in tubular collagen (Fig. 7). In a previous study that used this same animal model [10], histological analyses did not reveal either gross extracellular matrix expansion or gross pathology in the kidney. In the current study we obtained the same result using either haematoxylin and eosin staining or Masson's trichrome stain (for collagen) (data not shown).

\section{Discussion}

The goal of these studies was to evaluate the effects of a variety of renoprotective therapies on the formation of AGE/ALE and development of complications in the diabetic rat. At the doses employed, we were able to demonstrate significant protection against early nephropathy (creatininaemia, proteinuria, albuminuria) by each of the agents tested. These results are consistent with those of previous work from other laboratories using similar dosing regimens $[19,20,21,22,23,24$, $25,26]$. Enalapril, lipoic acid and vitamin E provided
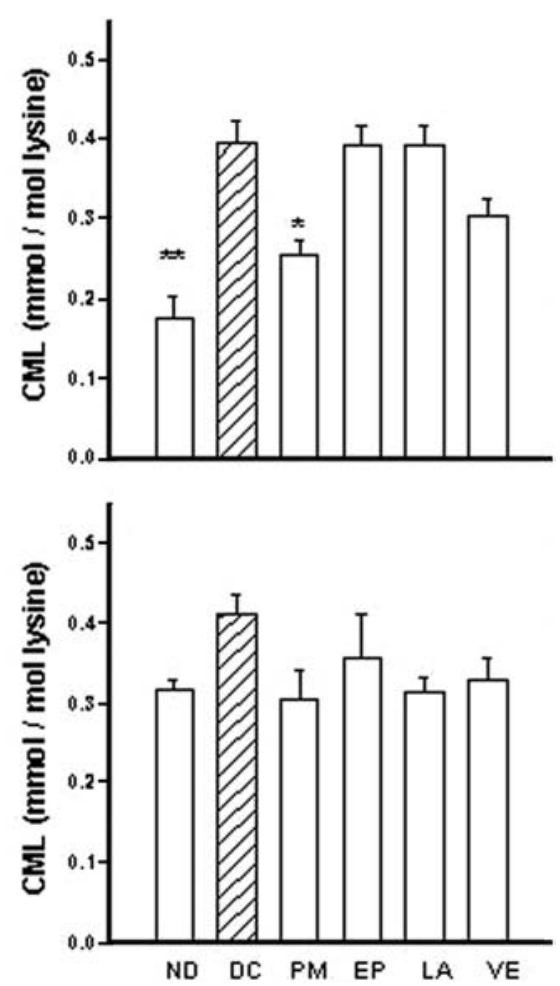

similar $(\sim 35 \%)$ inhibition of the increase in total urinary protein and albumin and plasma creatinine in diabetic compared with non-diabetic rats, while pyridoxamine produced a decrease of approximately 65\% toward normal values for these same measures. All of the agents prevented the increase in renal mRNA expression for the extracellular matrix proteins, fibronectin and laminin, and for the cytokine, TGF- $\beta_{1}$. Similarly, all interventions showed a modest effect on the urinary excretion of TGF- $\beta_{1}$. The dramatic changes in extracellular matrix protein and cytokine gene expression and protein synthesis did not correlate well with the more modest changes in plasma creatinine concentration and urinary albumin and total protein excretion. This suggests that the inhibition of the increase in gene expression and synthesis of pro-inflammatory cytokines was not sufficient in itself to protect against the decline in renal function in diabetic rats. Furthermore, pyridoxamine and lipoic acid inhibited the increase in plasma TNF- $\alpha$, whereas vitamin $\mathrm{E}$ and enalapril did not. This result conflicts with the order of efficacy of vitamin E, lipoic acid and enalapril on creatinaemia and proteinuria.

As reported previously [9], pyridoxamine inhibited the increase in CML, CEL and MDA-lysine, but not pentosidine in the skin collagen of diabetic rats. Despite partial protection of renal function, vitamin E, lipoic acid and enalapril did not significantly inhibit the increase in levels of these chemical modifications in skin collagen. However, there was a trend toward a decrease in all of the AGE/ALE biomarkers in the vitamin E group, but not in the LA or EP groups, which was consistent with their relative potency in reducing indicators of renal dysfunction (plasma creatinine and 
urinary protein and albumin). A similar trend was noted in the chemical analyses of AGE in glomeruli, with vitamin $\mathrm{E}$ having an effect that was intermediate between the diabetic control and pyridoxamine groups; however, the trend toward decreased CML did not reach statistical significance. These results were consistent with the immunohistochemical analyses shown in Fig. 8a, which also indicated that all of the agents had limited effects on the CML content of the glomeruli. Differences in the results of chemical analyses of protein modification in tubules did not reach statistical significance, although the trends were consistent with
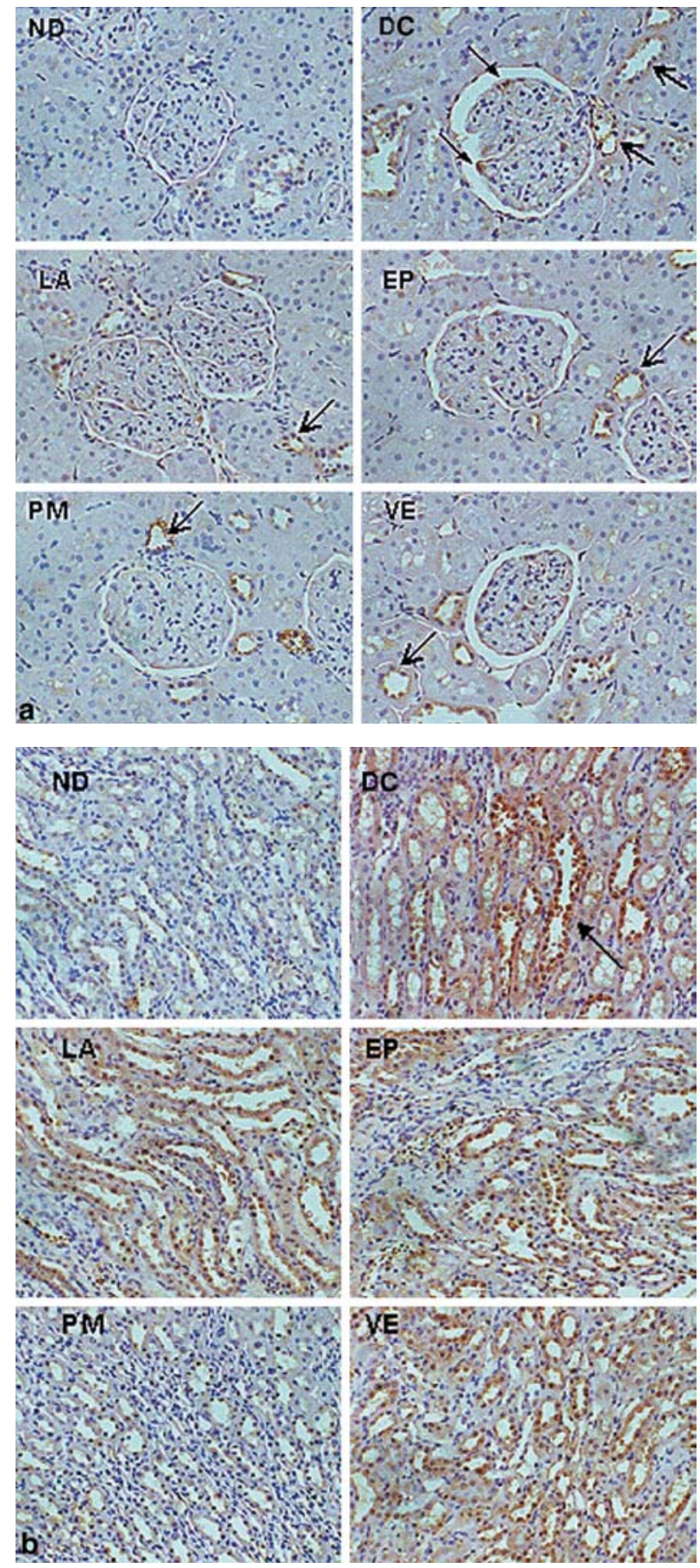

those observed for glomeruli. The fact that the strong CML staining in the proximal tubules of diabetic rats (Fig. 8b) was not associated with an increase in chemical AGE (Fig. 7), suggests that the majority of CML staining in tubules is the result of resorption and degradation of protein-bound and/or free AGE. Studies in rats [41], in renal cells in culture and in human renal tissue [42] have all demonstrated proximal tubule uptake of the AGE, pentosidine, in free or protein-bound form. Thus, the tubular AGE seen in diabetic kidney by immunohistochemistry are probably in the form of low-molecular-weight products in the endocytic and lysosomal compartments in the tubular cells and would be lost during the preparation of the tissue for analysis, which involves both trichloroacetic acid precipitation and extraction with organic solvents.

Overall, the results of these studies indicate that limited protection of renal function (as afforded by enalapril, lipoic acid and vitamin E) can occur in the absence of effects on AGE/ALE formation. In a recent study, the ACE inhibitor, ramipril, prevented the increase in renal AGE, in streptozotocin-diabetic rats, based on immunohistochemical staining of the kidney using a polyclonal anti-AGE antibody [12]. The differences in the effects of enalapril and ramipril suggest that, despite normalisation of hypertension by both agents, improvement in renal function does not require simultaneous inhibition of AGE/ALE formation. In the present study, although enalapril was not effective in inhibiting AGE/ALE formation, the overall order of inhibition of AGE/ALE accumulation was consistent with the order of protection of renal function. Higher doses of vitamin E or lipoic acid, significantly higher than those commonly used in studies in animal models, may show greater effects on the increase in AGE/ALE formation and loss of renal function in diabetes.

In addition to protecting renal function and decreasing AGE/ALE formation, pyridoxamine had a significant lipid-lowering effect in the streptozotocin-

Fig. 8. a. CML-immunoreactivity in rat glomeruli. For non-diabetic (ND) animals there is minimal immunoreactivity within the glomerulus in contrast to glomeruli in the diabetic control (DC) animals in which reaction product is evident (closed arrows). There is also intense tubular immunolocalisation of CML (open arrows). Treatment of rats with lipoic acid (LA), enalapril (EP), pyridoxamine (PM) and vitamin E (VE) all reduced CML immunoreactivity in the glomerulus compared with DC rats. However, in all treated groups, some tubular immunoreactivity was evident (open arrows). b. CML-immunoreactivity in rat tubules. CML-immunoreactivity in tubules of ND animals is sparse. In DC animals the immunoreactivity is intense and appears to be localised within the cytoplasm of the tubular epithelium (closed arrow). Treatment with LA, EP and VE did not appreciably alter the CML-immunoreactivity in the tubules; however, the intensity of staining in PM-treated samples was markedly lower than that in the DC group. Original magnification of all micrographs: $\times 200$ 
diabetic rat, without exhibiting a corresponding decrease in glycaemia. Because of the correlations demonstrated between proteinuria, albuminuria, CML in skin collagen and plasma triglyceride concentration in an earlier study [10], we proposed that lipids may be an important source of chemical modification of tissue proteins in the diabetic rat [43]. Indeed, increases in CML, CEL, MDA-lysine, 4-hydroxynonenal-lysine and pentosidine were also observed in the hyperlipidaemic, Zucker obese, non-diabetic rat [8]. Interestingly, vitamin E had a somewhat greater lipid-lowering effect than enalapril or lipoic acid, which was consistent with their order of efficacy in inhibiting renal disease and AGE/ALE formation, although in all cases this lipid-lowering effect was lower than that of pyridoxamine. The trend toward a decrease in MDA-lysine was also seen in the vitamin E group, suggesting that vitamin E may have both lowered lipid levels and inhibited the lipoxidative modification of proteins.

The present experiments indicate that the more effectively a therapeutic intervention limits the progression of nephropathy, the greater its effect on limiting AGE/ALE formation. For optimal protection of renal function during diabetic nephropathy, it would be beneficial to select drugs whose mechanism of action includes inhibition of AGE/ALE formation.

Acknowledgements. This work was supported by the Juvenile Diabetes Research Foundation (grant number 1-1999-796), National Institutes of Health (grant number DK19971), the Wellcome Trust Fight for Sight (UK) and the Research and Development Office (Northern Ireland).

\section{References}

1. Raj DSC, Choudhury D, Welbourne TC, Levi M (2000) Advanced glycation end products: a nephrologist's perspective. Am J Kid Dis 35:365-380

2. Stitt AW, Jenkins AJ, Cooper ME (2002) Advanced glycation end products and diabetic complications. Expert Opin Invest Drugs 11:1205-1223

3. Dyer DG, Dunn JA, Thorpe SR (1993) Accumulation of Maillard reaction products in skin collagen in diabetes and aging. J Clin Invest 91:2463-2469

4. Ceriello A (1999) Hyperglycaemia: the bridge between nonenzymatic glycation and oxidative stress in the pathogenesis of diabetic complications. Diabetes Nutr Metab 12:42-46

5. Nishikawa T, Edelstein D, Du XL et al. (2000) Normalizing mitochondrial superoxide production blocks three pathways of hyperglycaemic damage Nature 404:787-790

6. Suzuki D, Miyata T (1999) Carbonyl stress in the pathogenesis of diabetic nephropathy. Intern Med 38:309-314

7. Alderson NA, Chachich ME, Youssef NN et al. (2003) Pyridoxamine limits dyslipidemia, hypertension and early nephropathy in obese Zucker (fatty) rats. Kidney Int 63:2123-2133

8. Nilsson BO (1999) Biological effects of aminoguanidine: an update. Inflamm Res 48:509-515

9. Miyata T, Ueda Y, Asahi K et al. (2000) Mechanism of the inhibitory effect of OPB-9195 [(+/-)-2-isopropylidenehydrazono-4-oxo-thiazolidin-5-yla cetanilide] on advanced glycation end product and advanced lipoxidation end product formation. J Am Soc Nephrol 11:1719-1725

10. Degenhardt TP, Alderson NL, Arrington DD et al. (2002) Pyridoxamine inhibits early renal disease and dyslipidemia in the streptozotocin-diabetic rat. Kidney Int 61:939-950

11. Hamada Y, Nakamura J, Naruse K et al. (2000) Epalrestat, an aldose reductase inhibitor, reduces the levels of $\mathrm{N}^{\varepsilon_{-}}$(carboxymethyl)-lysine protein adducts and their precursors in erythrocytes from diabetic patients. Diabetes Care 23:1539-1544

12. Forbes JM, Cooper ME, Thallas V et al. (2002) Reduction of the accumulation of advanced glycation end products by ACE inhibition in experimental diabetic nephropathy. Diabetes 51:3274-3282

13. Nangaku M, Miyata T, Sada T et al. (2003) Anti-hypertensive agents inhibit in vivo the formation of advanced glycation end products and improve renal damage in a type 2 diabetic nephropathy rat model. J Am Soc Nephrol 14:1212-1222

14. Jerums G, Panagiotopoulos S, Forbes J, Osicka T, Cooper M (2003) Evolving concepts in advanced glycation, diabetic nephropathy, and diabetic vascular disease. Arch Biochem Biophys 419:55-62

15. Way KJ, Katai N, King GL (2001) Protein kinase C and the development of diabetic vascular complications. Diabet Med 18:945-959

16. Frank RN (2002) Potential new medical therapies for diabetic retinopathy: protein kinase $\mathrm{C}$ inhibitors. Am J Ophthalmol 133:693-698

17. Usui H, Shikata K, Matsuda M et al. (2003) HMG-CoA reductase inhibitor ameliorates diabetic nephropathy by its pleiotropic effects in rats. Nephrol Dial Transplant 18:265-272

18. Babaei-Jadidi R, Karachalias N, Ahmed N, Battah S, Thornalley PJ (2003) Prevention of incipient diabetic nephropathy by high-dose thiamine and benfotiamine. Diabetes 52:2110-2120

19. Koya D, Lee IK, Ishii H, Kanoh H, King GL (1997) Prevention of glomerular dysfunction in diabetic rats by treatment with d-alpha-tocopherol. J Am Soc Nephrol 8:426-435

20. Craven PA, DeRubertis FR, Kagan VE, Melhem M, Studer RK (1997) Effects of supplementation with vitamin C or E on albuminuria, glomerular TGF-beta, and glomerular size in diabetes. J Am Soc Nephrol 8:1405-1414

21. Kim SS, Gallaher DD, Csallany AS (2000) Vitamin E and probucol reduce urinary lipophilic aldehydes and renal enlargement in streptozotocin-induced diabetic rats. Lipids 35:1225-1237

22. Stevens MJ, Obrosova I, Cao X, Van Huysen C, Greene DA (2000) Effects of DL-alpha-lipoic acid on peripheral nerve conduction, blood flow, energy metabolism, and oxidative stress in experimental diabetic neuropathy. Diabetes 49:1006-1015

23. Melhem MF, Craven PA, Liachenko J, DeRubertis FR (2002) Alpha-lipoic acid attenuates hyperglycemia and prevents glomerular mesangial matrix expansion in diabetes. J Am Soc Nephrol 13:108-116

24. Melhem MF, Craven PA, Derubertis FR (2001) Effects of dietary supplementation of $\alpha$-lipoic acid on early glomerular injury in diabetes mellitus. J Am Soc Nephrol 12:124-133

25. Obrosova IG, Fathallah L, Liu E, Nourooz-Zadeh J (2003) Early oxidative stress in the diabetic kidney: effect of DLalpha-lipoic acid. Free Rad Biol Med 34:186-195

26. Packer L, Kraemer K, Rimbach G (2001) Molecular aspects of lipoic acid in the prevention of diabetes complications. Nutrition 17:888-895 
27. Januszewski AS, Alderson NL, Metz TO, Thorpe SR, Baynes JW (2003) Role of lipids in chemical modification of proteins and development of complications in diabetes. Biochem Soc Trans 31:1413-1416

28. Dunn JA, McCance DR, Thorpe SR, Lyons TJ, Baynes JW (1991) Age-dependent accumulation of $\mathrm{N}^{\varepsilon}$ (carboxymethyl)lysine and $\mathrm{N}^{\varepsilon-}$ (carboxymethyl)hydroxylysine in human skin collagen. Biochemistry 30:1205-1210

29. Requena JR, Fu M-X, Ahmed MU et al. (1997) Quantification of malondialdehyde and 4-hydroxynonenal adducts to lysine residues in native and oxidized human low-density lipoprotein. Biochem J 322:317-325

30. Dyer DG, Blackledge JA, Thorpe SR, Baynes JW (1991) Formation of pentosidine during nonenzymatic browning of protein by glucose: identification of glucose and other carbohydrates as possible precursors of pentosidine in vivo. J Biol Chem 266:11654-11660

31. Kreisberg JI, Karnovsky MJ (1983) Glomerular cells in culture. Kidney Int 23:439-447

32. Abrass CK, Spicer D, Raugi GK (1994) Insulin induces a change in extracellular matrix glycoproteins synthesized by rat mesangial cells in culture. Kidney Int 46:613-620

33. Peterson GL (1979) Review of the Folin phenol protein quantitation method of Lowry, Rosebrough, Farr and Randall. Anal Biochem 100:201-220

34. Requena JR, Price DL, Thorpe SR, Baynes JW (1999) Measurement of pentosidine in biological samples. In: Barnett Y, Barnett CR (eds) Methods in molecular medicine, vol 38: Aging, methods and protocols. Humana Press, N.J., pp 209-217

35. Simpson DA, Murphy GM, Bhaduri T, Gardiner TA, Archer DB, Stitt AW (1999) Expression of the VEGF gene family during retinal vaso-obliteration and hypoxia. Biochem Biophys Res Commun 262:333-340
36. Simpson DA, Feeney S, Boyle C, Stitt AW (2000) Retinal VEGF mRNA measured by SYBR green I fluorescence: a versatile approach to quantitative PCR. Mol Vis 6:178-183

37. Stitt A, Gardiner TA, Alderson NL et al. (2002) The AGE inhibitor pyridoxamine inhibits development of retinopathy in experimental diabetes. Diabetes 51:2826-2832

38. Thorpe SR, Alderson NL, Chachich ME et al, (2002) Role of dyslipidemia and AGE/ALE formation in the progression of nephropathy and retinopathy in STZ-diabetic rats. Excerpta Med 1245:169-173

39. Mogyorosi A, Kapoor A, Isono M, Kapoor S, Sharma K, Ziyadeh FN (2000) Utility of serum and urinary transforming growth factor-beta levels as markers of diabetic nephropathy. Nephron 86:234-235

40. Ziyadeh FN, Hoffman BB, Han DC et al. (2000) Longterm prevention of renal insufficiency, excess matrix gene expression, and glomerular mesangial matrix expansion by treatment with monoclonal antitransforming growth factorbeta antibody in $\mathrm{db} / \mathrm{db}$ diabetic mice. Proc Natl Acad Sci USA 97:8015-8020

41. Miyata T, Ueda Y, Horie K et al. (1998) Renal catabolism of advanced glycation end products: the fate of pentosidine. Kidney Int 53:416-422

42. Fujita A, Ueda Y, Suzuki D, Miyata T, Sakai H, Saito A (2002) Renal proximal tubular metabolism of proteinlinked pentosidine, an advanced glycation end product. Nephron 91:688-694

43. Januszewski AS, Alderson NL, Metz TO, Thorpe SR, Baynes JW (2003) Role of lipids in chemical modification of proteins and development of complications in diabetes. Biochem Soc Trans 31:1413-1416 